\title{
O Texto Literário no Ensino DAS LÍNGUAS EsTRANGEIRAS: DOS Métodos Tradicionais À ABordagem Comunicativa
}

\section{Elisabetta Santoro}

RESUMO Muito já se escreveu sobre a relação entre língua e literatura e sobre o papel do texto literário no ensino/aprendizagem das línguas estrangeiras. Neste artigo pretendemos refletir sobre como se desenvolveram as convicções sobre a função da literatura no ensino das línguas, tomando como exemplo a Universidade de São Paulo e a criação de seu curso de Letras para ilustrar algumas características dos métodos tradicionais. Em seguida, procuraremos analisar como se transformou o papel da literatura na didática das línguas estrangeiras até chegar à abordagem comunicativa.

PALAVRAS-CHAVE língua estrangeira; texto literário; didática das línguas. 
ABSTRACT Si è già scritto molto sul rapporto fra lingua e letteratura e sul ruolo del testoletterarionell'insegnamento/apprendimento delle lingue straniere. In questo articolo si riflette sulla maturazione di convinzioni riguardanti la funzione della letteratura nell'insegnamento delle lingue, prendendo come esempio l'Università di São Paolo e la creazione del corso di Laurea in Lettere, allo scopo di illustrare alcune caratteristiche dei metodi tradizionali. Sarà, in seguito, analizzata la trasformazione del ruolo della letteratura nella didattica delle lingue straniere fino all'approccio comunicativo.

PAROLE CHIAVE lingua straniera; testo letterario; didattica delle lingue.

ABSTRACT A lot has been written about the relation between language and literature and about the role of the literary text in teaching and learning foreign languages. In this article we will try to reflect about how have been developed convictions about the function of literature in language teaching, taking as example the University of São Paulo and the creation of its course of Letters, in order to illustrate some characteristics of the traditional methods. Then, we will analyze how the role of literature in the didactics of foreign languages has changed until the communicative approach. KEY'WORDS foreign language; literary text; didactics oflanguages. 


\section{Introdução}

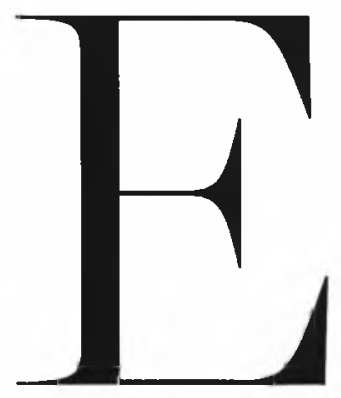

m texto publicado em espanhol em 1977 e traduzido para o português em 1982, o lingüista romeno Eugenio Coseriu postula a identidade entre linguagem e poesia, já que, diz ele, apenas a linguagem poética ativa uma complexa rede de relações que nos outros usos lingüísticos se tornam inoperantes:

Por conseguinte, a linguagem poética revela-se, não um uso lingüístico entre outros, mas linguagem simplesmente (sem adjetivos): realização de todas as possibilidades da linguagem como tal. (1982: 146)

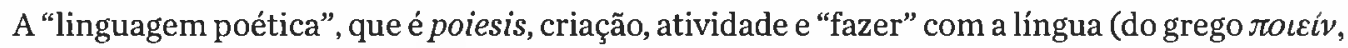
fazer), representaria, segundo essa visão, a "plena funcionalidade" da linguagem. Por isso, os textos poéticos seriam o lugar mais rico dos desdobramentos da língua, necessários para observá-la e estudá-la, enquanto as outras manifestações lingüísticas seriam usos específicos da linguagem, reduções que não desenvolvem todas as suas virtualidades.

Pode-se discutir se a hipótese da absoluta coincidência entre linguagem e poesia é sustentável ou não. A certa altura o próprio Coseriu parece contradizê-la. De qualquer maneira, ela nos confronta com uma questão muito discutida e polêmica: a questão da relação entre língua e literatura, entre o texto literário e a língua de que é feito.

Muito já foi escrito sobre esse assunto e muitos argumentaram em favor da necessidade de união entre esses dois campos do saber, defendendo que língua e literatura constituem um binômio inseparável, visto que a língua não seria pensável sem a literatura e a literatura não seria possivel sem a língua. 
De fato, a lingua estabelece relações, traça fronteiras, produz conceitos, transmite idéias, veicula interpretações e tudo isso é indispensável para que se faça literatura, que só pode ser realmente "descoberta" analisando e lendo em profundidade a língua que a constitui.

Por outro lado, a literatura abre novos espaços, admite contradições, permite jogos, comporta ambigüidades, amplia potencialidades e tudo isso é imprescindivel para entender e conhecer a língua, inclusive porque, como diz Denis Bertrand, "a literatura exerce [...] por natureza, uma função crítica sobre a língua, desaprumando-a em relação a si mesma em cada obra” (2003:25).

Língua e literatura são, contudo, ainda hoje, em muitas situações, domínios separados, são tratadas como disciplinas distintas e, portanto, ensinadas e estudadas sem estabelecer contatos ou criar ligações. Embora unidas em nomes de cursos universitários e pronunciadas como sintagma coeso e sólido em tantas ocasiões, elas permanecem, na maior parte dos casos, dois campos separados do saber e, ainda que o texto literário possa ser considerado um lugar de encontro, o que justificaria a diluição da dicotomia língua/literatura, tanto nas escolas, quanto nas universidades, uma efetiva integração até hoje não se realizou.

De fato, a nosso ver, a literatura é o texto literário, o qual, por essa razão, deveria representar a base de qualquer curso de literatura, em qualquer nível e em qualquer situação. Por outro lado, o texto literário, enquanto realização de todas as potencialidades da linguagem, possui um papel essencial para que ela possa ser estudada e não poderia, portanto, ser excluído dos cursos de língua materna ou estrangeira. Levando em conta isso, reputamos indispensável a reflexão sobre intersecções e confluências entre essas duas áreas que, aparentemente divididas por intransponíveis barreiras metodológicas, na verdade, são, ou podem ser, uma só.

Ainda que muitas de nossas reflexões sobre língua e literatura não sejam específicas de uma determinada situação de ensino, concentrar-nos-emos na realidade em que atuamos e tomaremos, portanto, como referência a Área de Língua e Literatura Italiana do curso de Letras da Faculdade de Filosofia, Letras e Ciências Humanas da Universidade de São Paulo. Isso significa que especial atenção será dedicada a considerações sobre os cursos de Letras em geral, sobre a formação dos profissionais das Letras e sobre as peculiaridades do ensino das Línguas e das Literaturas Estrangeiras e, mais especificamente, da Língua e da Literatura Italiana para falantes de português.

\section{A tradição dos cursos de Letras}

Os cursos de Letras refletem a divisão que acompanha desde sempre os campos dos estudos literários e dos estudos lingüísticos. Em seu conhecido ensaio "Lingüística e poética". originalmente apresentado como conferência na Indiana University em 1958, Jakobson mostrou, de forma clara e contundente, como lingüistas e estudiosos da literatura raramente dialogam e quanto 
cada uma das duas áreas poderia avançar, se não ignorasse a outra. Jakobson conclui sua argumentação com a seguinte afirmação:

[...] um lingüista surdo à função poética da linguagem e um especialista de literatura indiferente aos problemas lingüísticos e ignorante dos métodos lingüísticos são, um e outro, flagrantes anacronismos. (1977:162)

Essas reflexões não parecem ter influenciado os rumos dos cursos de Letras. Desde o início de suas vidas acadêmicas, os alunos vivem língua e literatura como mundos separados e são levados, pela própria organização curricular, a perceber mais as diferenças do que as analogias entre essas duas disciplinas. De fato, pela maneira como são estruturados, os cursos induzem-nos a formar-se numa lógica da separação, numa mentalidade dos compartimentos estanques, que reforça e reitera um rígido sistema de ensino, no qual se prefere a comodidade da repetição de esquemas consolidados ao desafio da integração.

Para melhor entender como se originaram algumas das crenças que, em parte, perduram até hoje, tanto na estrutura do curso, quanto na maneira como são ensinadas as línguas e as literaturas estrangeiras, pode ser útil observar como foram dados os primeiros passos dos cursos de Letras no Brasil. Tomaremos como exemplo o curso da então Faculdade de Filosofia, Ciências e Letras da Universidade de São Paulo, fundado não só nessa “cultura da divisão", mas também na convicção da superioridade dos estudos literários em relação aos estudos lingüísticos.

Entre 1937 e 1954, a Faculdade promoveu a publicação de Anuários relativos aos anos de 1934 (ano de sua criação) a 1952. Entre outras coisas, nos Anuários eram descritos os diferentes cursos da Faculdade, eram fornecidos dados numéricos e eram transcritas as aulas inaugurais, os programas e os objetivos das disciplinas. Além disso, os professores responsáveis pelas diferentes cátedras eram convidados a escrever artigos, nos quais expunham sua experiência na Faculdade, discorriam sobre a relevância dos estudos em suas disciplinas e sobre seu possível desenvolvimento, dando inclusive sugestões a respeito de como poderia ser melhorado o ensino universitário.

É significativo para as nossas considerações sobre estudos lingüísticos e estudos literários ler no texto do professor Francisco da Silveira Bueno que "para os lingüistas, as qualidades literárias do texto de pouco ou nada valem" (Anuário, 1953: 85), porque eles estariam interessados na língua como tal e, portanto, não na literatura. O escrito do professor de Filologia visava a evidenciar as diferenças entre lingüistas e filólogos - aqueles atraídos apenas pela "língua em que está escrito o documento", enquanto para estes "a língua é apenas um instrumento, um auxiliar que (...) ajuda a criticar o escrito, a avaliar sua época” (Anuário, 1953:85) -, mas dá claros indícios sobre a maneira como eram vistos os lingüistas e a lingüística e sobre a distância que, segundo se considerava, existia entre o mundo da língua e o da literatura. 
Na nossa busca de indicações quanto às relações entre língua e literatura, encontramos sinais ainda mais evidentes de separação nos relatórios das cadeiras de Línguas e Literaturas Estrangeiras. Nelas são mencionados, às vezes, cursos e aulas de língua, dos quais não se encontram, porém, referências nos programas, já que estes contêm exclusivamente tópicos de literatura.

Lendo, por exemplo, o primeiro programa do professor Francesco Piccolo, que ocupou em 1934 a cátedra de Língua e Literatura Italiana,' observamos que ele prevê o estudo de Dante, Angelo Poliziano, Lorenzo de' Medici e Ariosto para ilustrar alguns momentos essenciais da literatura italiana, mas não faz menção alguma ao estudo da língua e a como esse se daria (Anuário, 1937:294). Os programas dos anos seguintes são redigidos nos mesmos moldes do primeiro.

Quando, em 1937, Giuseppe Ungaretti é chamado da Itália para substituir o antigo professor, em seu primeiro programa faz constar, além do programa de literatura, uma parte dedicada à lingua. No entanto, o tema previsto nada tem em comum com um estudo lingüístico assim como o entendemos hoje: o programa propõe o estudo da teoria sobre a língua de Leopardi e a leitura da obra do poeta com comentários de seus textos (Anuário, 1938:364).

Bastam essas observações para perceber que a tradição do curso de Letras da USP não só separa língua e literatura, mas enfatiza a literatura em detrimento à língua: não havia interesse no ensino das línguas - em especial, das línguas estrangeiras - e os professores lamentavam que os estudantes não chegassem à universidade com conhecimentos prévios, porque isso significava não poder "elevar-se dos conhecimentos das línguas ao conhecimento histórico e crítico das literaturas" (Anuário, 1937:211), como escreve o professor Piccolo, referindo-se em especial à falta do estudo das línguas clássicas no currículo escolar, já que - afirma o professor - os alunos "balbuciam o italiano ou o francês [e] não conhecem sequer os primeiros elementos da língua latina ou da língua grega" (Anuário, 1937:210).

Uma queixa do mesmo tipo está presente também no Anuário relativo aos anos de 1939 a 1949. No volume em que são indicadas e comentadas as atividades docentes, há um relatório da cadeira de Língua e Literatura Italiana e, a uma certa altura, lê-se o seguinte:

Os candidatos à Faculdade de Filosofia ingressam nos cursos da Cadeira sem que lhes seja exigido, por exame, qualquer conhecimento de Língua ou Literatura Italiana. É esta uma situação insustentável que poderia ser corrigida com a inclusão do estudo do italiano no $2^{\circ}$ ciclo do ensino médio como cadeira de livre escolha ou como disciplina de um curso pré-universitário. (1953:494)

Vê-se que a língua estrangeira é mencionada, mas apenas como instrumento para que possam ser lidos os textos literários originais. Em outras palavras: a língua estava a serviço da literatura, era pensada como conhecimento prévio das formas, do léxico e da gramática, que pudesse permitir compreender os textos de literatura estrangeira, estes sim vistos como a essência do curso, 
como aquilo que realmente contava na formação (cf. também Fiorin, 2007:100-101). Os alunos deviam concentrar-se nos estudos mais nobres e "elevados" da literatura e a aprendizagem das línguas estrangeiras não devia, nem podia ter lugar dentro da universidade, onde se almejava uma instrução "verdadeiramente superior" e onde, portanto, a língua deveria ser um pré-requisito.

É evidente que o conhecimento da língua não implicava, nessa concepção, reflexões lingüísticas eque a atividade de ensinar uma língua (e aqui pensamos especialmente nas línguas estrangeiras) era, por isso, considerada inadequada ao contexto universitário, redoma dos intelectuais da interpretação literária epifânica e magistral, a que se chegava pela erudição, pela história, pelo estudo da crítica e dos críticos, e não pelo conhecimento profundo da língua e do seu funcionamento.

\section{O ensino de línguas estrangeiras e o texto literário: dos métodos tradicionais à abordagem comunicativa}

Embora tivesse sido abertamente declarado não se considerar a universidade lugar adequado para isso, os cursos de Letras foram obrigados a encarregar-se também do ensino das línguas estrangeiras. Os currículos escolares do ensino fundamental e médio não previam o estudo de todas as linguas estrangeiras clássicas e modernas incluídas nesses cursos superiores e houve até épocas nas quais era possível concluir o percurso escolar sem nunca ter estudado sequer uma única língua estrangeira (Leffa, 1999:10). A universidade teve, portanto, de preparar os alunos para que pudessem iniciar suas carreiras universitárias na área das Letras, aprendendo as línguas estrangeiras para dedicar-se, depois da prática com a língua, aos estudos literários, que eram o que realmente importava.

Como já ressaltamos, nesse período o ensino do idioma era um ensino baseado na gramática, no léxico e nos exercícios de classificação. Além disso, no caso de uma língua não-materna, a atenção estava dirigida, antes de tudo, a aprender as maneiras "corretas" de expressar-se no outro sistema lingüístico. As línguas eram consideradas conglomerados de estruturas gramaticais e palavras isoladas, que, uma vez estudadas e treinadas com listas e traduções, permitiriam a leitura dos textos, sobretudo os literários, que eram o objetivo final de todo o processo de aprendizagem. A metodologia tradicional previa, em suma, um único ponto de intersecção entre o ensino da língua e o ensino da literatura: o código lingüístico utilizado.

Nesse contexto, não é difícil imaginar que os textos literários possuíam um papel essencial nas aulas; eles eram, aliás, os únicos textos de referência, porque continham a língua que devia ser imitada e entendida. É por isso que geralmente se associa o uso da literatura na sala de aula de língua estrangeira às abordagens didáticas ditas tradicionais, nas quais o texto literário, julgado 
respeitoso das normas gramaticais e exemplo de uma "boa" realização lingüística, era o modelo que apresentava a língua correta e elevada ao aluno estrangeiro. O texto literário era, portanto, tratado como distante objeto de veneração, visto "[...] como aquilo que devíamos alcançar e como aquilo que jamais alcançaríamos. Falávamos dele, mas raramente com ele e muito menos dentro dele”, diz González descrevendo a posição dos aprendizes de línguas estrangeiras (1990:117). ${ }^{2}$ $\mathrm{E}$, de fato, o objetivo não era criar as condições para que os alunos pudessem "estabelecer uma vivência" com o texto literário, o qual, ao contrário, incorporando os valores de um determinado tipo de ensino, era visto como norma, perfeição, estabilidade, elevação do espírito, distância da banalidade do cotidiano e da língua utilitária e corrente.

À medida que as metodologias para o ensino das línguas estrangeiras foram mudando e que a dita "abordagem comunicativa" se foi afirmando, o texto literário foi, cada vez mais, substituído por textos que se acreditava pudessem refletir de forma mais fiel a língua falada e cotidiana, isto é, a língua da "verdadeira comunicação". Os adeptos dessa visão do ensino de línguas estrangeiras rejeitaram a idéia da importância do texto literário e, reagindo aos modelos antes vigentes, inverteram completamente a rota: em sua, a nosso ver, errônea interpretação do que é competência comunicativa, não consideraram "comunicativo" o texto literário e, portanto, não julgaram que pudesse ser integrado num ensino da lingua estrangeira, no qual se ia consolidando a idéia de que era necessário concentrar-se na comunicação da "vida real" e nas funções da linguagem, que permitem aprender a fala utilitária do dia-a-dia. Era essa a língua que devia ser estudada antes e sem a interferência de textos tão distantes do cotidiano como os textos literários, os quais prejudicariam ou retardariam a aquisição da competência comunicativa. ${ }^{3}$

A partir desse periodo, a literatura perdeu, portanto, seu papel central nas aulas de línguas estrangeiras, o que acentuou a separação entre o ensino de língua e de literatura. Eventualmente ela era utilizada apenas nos niveis avançados dos cursos de língua e essa convicção é até hoje extremamente difundida: considera-se que um aluno que ainda não conhece profundamente a língua estrangeira não pode entender os aspectos mais especificamente “literários" dos textos e que, portanto, é necessário prepará-lo antes; em outras palavras, prevalece a lógica que impõe, numa escala cujos critérios não são sempre facilmente compreensíveis, que o fácil (a língua) anteceda o difícil (a literatura) e que o cotidiano e a "realidade" (a língua com função utilitária) venham antes do incomum e da "ficção" (a lingua com função estética).

Curiosamente, a partir do auge da abordagem comunicativa, afirmou-se, portanto, uma posição que, em relação à presença da literatura na sala de aula de língua estrangeira, revela mais pontos de contato com a concepção tradicional, que - como vimos - tratava o texto literário como objeto de "veneração", do que com as metodologias posteriores, nas quais começaram a ganhar espaço visões muito mais dinâmicas e abrangentes de língua e de aprendizagem.

Em épocas mais recentes, somou-se a isso a opinião de alguns docentes e especialistas em didática das línguas estrangeiras, que afirmaram considerar desnecessário o uso de textos literários como

2. O texto do qual foi extraída essa citação foi publicado em espanhol ("[...] como aquello que debiamos alcanzar y como aquello que jamás alcanzaríamos. Hablábamos de él, pero raramente con él y mucho menos en él'). Nesse caso, como em todos os outros em que o texto consta na bibliografia numa língua diferente do português, a tradução é nossa e o original será transcrito em nota.

3. Muito foi escrito sobre a "abordagem comunicativa" e muitas são as indicações bibliográficas possiveis. Remetemos ao texto "clássico" The Communicative Approach to Language Teaching, organizado por Brumfit e Johnson (1979). 
material didático, dada a abundância de textos que jornais, revistas, televisão e, principalmente, a internet nos colocam à disposição, iterando também que um aprendiz só pode dar conta de um texto literário, quando tiver alcançado um nível avançado no estudo da língua estrangeira.

É claro que essas posições não consideram os aspectos peculiares da função poética do texto literário, que, tratado como apenas mais um tipo de texto, é privado de seu potencial específico e identificado como o texto "difícil", além de sofrer uma sorte de "preconceito ao contrário": por ter sido já tão valorizado pelos métodos tradicionais, defender sua utilização em sala de aula soa aos ouvidos de muitos como anacronismo.

Mesmo o Quadro europeu comum de referência para as línguas: aprendizagem, ensino e avaliação (QECR), documento elaborado por vários especialistas em ensino/aprendizagem de línguas estrangeiras e publicado pelo Conselho da Europa em $2001^{4}$ como resultado de anos de estudos e pesquisas, raramente menciona os textos literários e, quando o faz, também considera a literatura como leitura para aprendizes nos últimos níveis (C1-C2), que se prepararam com textos cotidianos antes de estar prontos para "entender" o texto literário (cf. QECR, 2001:53).

Assim, acontece ainda hoje que muitos livros didáticos para o ensino de línguas estrangeiras, ${ }^{5}$ mesmo quando dão algum espaço ao texto literário, restringem sua utilização aos níveis avançados e oscilam entre a visão tradicional, que o identificava com o modelo "sacralizado" de bom uso da língua, e a banalização das suas potencialidades. $\mathrm{O}$ trabalho com o texto limita-se, de fato, ao denotativo è̀ exemplaridade da língua utilizada.

Com a finalidade de verificar a "compreensão" são elaborados questionários, aos quais o aprendiz deve responder após a leitura. Muitas vezes, esses questionários são pouco ou nada desafiadores, pois as perguntas são óbvias e têm como objetivo verificar apenas a compreensão do que diz o texto em língua estrangeira. Uma vez comprovado que os alunos o “entenderam”, ele pode ser usado para observar as estruturas gramaticais que contém e como ponto de partida para exercícios. Há também livros didáticos que partem da temática abordada e usam-na como estímulo para a conversação em sala de aula ou para a produção de um texto escrito, de forma que o aprendiz possa praticar a língua estrangeira e exercitar o que está aprendendo.

A conseqüência é que, num movimento contrário ao da ênfase na literatura, o aspecto mais especificamente literário (estético, múltiplo, denso) do texto é sacrificado para que se alcance a compreensão do enredo, da mensagem, do referente, da denotação, sem que se indique ao aprendiz quais são os caminhos por meio dos quais é gerado o sentido e sem que sejam exploradas as possiveis interpretações. Ou seja: a partir da leitura não se iniciam reflexões mais profundas sobre o funcionamento do texto, sobre os sentidos nele contidos e sobre a maneira como se dá a significação.

Por outro lado, em atividades didáticas como as que acabamos de descrever, a observação da língua pára no enunciado, só dá lugar à reutilização de formas e não constitui o ponto de partida para análises mais detalhadas e para poder aprender a perceber a gramática no texto como

4. O título completo do documento no original em inglês é: Common European Framework of Reference for Languages: Learning, Teaching, Assessment. Em 2001 o volume foi publicado pelo Conselho da Europa em inglês e francês e, logo em seguida, foram encomendadas e realizadas as traduções na maior parte das línguas dos países da União Européia. Para o presente trabalho utilizamos a versão portuguesa (2001) e a italiana (2002). O Quadro Europeu Comum de Referência (QECR) divide em seis niveis gerais a organização da aprendizagem das línguas e indica descritores para que os aprendizes possam ser classificados nos diferentes níveis, que são: Al (iniciação), A2 (elementar), Bl (limiar), $\mathrm{B} 2$ (vantagem), C1 (autonomia), C2 (mestria). Há ainda a denominação utilizador elementar para A1 e A2, utilizador independente para $\mathrm{B} 1 \mathrm{e}$ $\mathrm{B} 2$ e utilizador proficiente para $\mathrm{Cl}$ e C2 (QECR, 2001: 48).

5. Os manuais, aos quais nos referimos aqui, são especialmente os de Italiano como língua estrangeira, inclusive os mais recentes. Em geral e pelo que conhecemos, o tratamento dos textos literários nāo é muito diferente também na maioria dos livros didáticos para outras línguas estrangeiras. 
elemento que contribui para a criação de (novos) significados. A chamada "reflexão sobre a língua", que muitos manuais didáticos incluem, limita-se geralmente a uma reconstrução, com base em elementos observados no texto, de como pode ser sistematizada uma "regra" gramatical e de quais são as normas que regem seu "uso", sendo que, em geral, não há espaço para efetivos questionamentos sobre os efeitos de sentido gerados e sobre como eles influenciam a leitura e a interpretação do texto.

Dessa maneira, deixa-se inutilizado o aspecto mais significativo da criação literária, aquilo que a transforma em algo especial, como muito bem escreve Graciela Reyes, afirmando que:

[...] citar a literatura como exemplo de língua culta prestigiosa [...] é um erro que surge da crença de que a literatura é a culminação do falar bem da comunidade. A literatura é muito mais do que isso, a partir de uma perspectiva lingüística: a literatura é um experimento que supõe um falar bem, consolida-o e perverte-o para inová-lo. ${ }^{6}$

Eis um dos pontos que nos levam a propor a integração do ensino de língua e de literatura: o texto literário consolida, transforma, inova, equilibra éé, portanto, um texto cujas potencialidades são fundamentais no ensino em geral e indispensáveis para os alunos dos cursos de Letras, que, em sua formação, precisam de sólidos conhecimentos literários e de profundos conhecimentos lingüísticos para aprender a analisar, observar e vivenciar a linguagem.

Isso se torna ainda mais essencial, quando se aprende uma língua estrangeira e se estuda sua literatura, já que, só na observação das confluências e na interação entre uma área e outra, o processo de aprendizagem pode tentar apreender a complexidade que representa o contato com um mundo outro por meio da linguagem, vista não apenas como um "instrumento", mas como a essência do ser humano, aquilo que realmente o constitui.

6. '[...] citar la literatura como ejemplo de lengua culta prestigiosa [...] es un error que surge de la creencia de que la literatura es la culminación del bien hablar de la comunidad. La literatura es mucho más que eso, desde una perspectiva linguistica: la literatura es un experimento que supone un bien hablar, lo consolida y lo pervierte para inovarlo" (REYEs, 1984: 193). 


\section{Referências Bibliográficas}

Anuário da Faculdade de Filosofia, Ciências e Letras 1934-1935 (1937). São Paulo: Revista dos Tribunaes.

Anuário da Faculdade de Filosofia, Ciências e Letras 1936 (1937a). São Paulo: Faculdade de Filosofia, Ciências e Letras.

Anuário da Faculdade de Filosofia, Ciências e Letras 1937-1938 (1938). São Paulo: Faculdade de Filosofia, Ciências e Letras.

Anuário da Faculdade de Filosofia, Ciências e Letras 1939-1949 (1953). São Paulo: Faculdade de Filosofia, Ciências e Letras, v. I e II.

Anuário da Faculdade de Filosofia, Ciências e Letras 1950 (1952). São Paulo: Faculdade de Filosofia, Ciências e Letras. Anuário da Faculdade de Filosofia, Ciências e Letras 1951 (1952a). São Paulo: Faculdade de Filosofia, Ciências e Letras.

Anuário da Faculdade de Filosofia, Ciências e Letras 1952 (1954). São Paulo: Faculdade de Filosofia, Ciências e Letras. Bertrand, Denis (2003). Caminhos da semiótica literária. Tradução do Grupo Casa Bauru: Editora da Universidade do Sagrado Coração.

Brumfit, Chistopher \& Johnson, Keith (orgs.) (1979). The Communicative Approach to Language Teaching. Oxford: Oxford University Press.

Conselho da Europa (2001). Quadro europeu comum de referência para as línguas. Aprendizagem, ensino, avaliação. Tradução do inglês de Maria Joana Pimentel do Rosário e Nuno Verdial Soares. Porto/Lisboa: Asa Edições.

Consiglio d'Europa (2002). Quadro comune europeo di riferimento per le lingue. Apprendimento, insegnamento, valutazione. Tradução do inglês de Franca Quartapelle e Daniela Bertocchi. Milão: RCS Scuola/Florença: La Nuova Italia.

Coseriu, Eugenio (1982). “Teses sobre o tema 'linguagem e poesia'". In: Coseriu, E. O homem e sua linguagem. Estudos de teoria e metodologia lingüística. Tradução de Carlos Alberto da Fonseca e Mário Ferreira. Rio de Janeiro: Presença/São Paulo: Editora da Universidade de São Paulo, p. 145-149.

Fiorin, José Luiz (2007). "A criação dos cursos de Letras no Brasil e as primeiras orientações da pesquisa lingüística universitária". In: Fávero, Leonor Lopes, Bastos, Neusa Barbosa \& Marquesi, Sueli Cristina. Língua Portuguesa: pesquisa e ensino. São Paolo: Editora da PUCSP, v. I, p. 93-104.

González, Neide T. Maia (1990). “La utilización del texto literario en las clases de lengua extranjera”. In: Silva, Pedro Câncio da (org). Língua, literatura e integraçâo hispano-americana. Porto Alegre: SEC, Editora da UFRGS, p. 116-123.

Jakobson, Roman (1977). Lingüística e comunicação. Prefácio de Izidoro Blikstein. Tradução de Izidoro Blikstein e José Paulo Paes. São Paulo: Cultrix.

Leffa, Vilson J. (1999). O ensino de línguas estrangeiras no contexto nacional. Contexturas, APLIESP, n. 4, p. 13-24.

Reyes, Graciela (1984). Polifonía textual. La citación en el relato literario. Madri: Gredos. 